\title{
Modeling of Hydraulic Power Cylinder Seal Assembly Operation BUYALICH Gennady $D^{1,2}$, BUYALCH Konstantin $\mathbf{G}^{\mathbf{1}}$
}

\section{Mininginetitute, T.I. Gorbachev KuxbaedState Technical Untvernity,650000 Kemerovo, Rusila; \\ 2.Yurea Institute of Technology of Tomal Technical Untversity, 652055 Yuren,} Rusia

Abatract: The nature of the hydraulic power cylinder seal assembly operation with high working fluid pressure, different geometrical parameters of liptype seal, is revealed. The method of hermetic sealing process modeling according to the simplified model using finite element method is considered.

Keywords: finite element method, modeling, hydraulic power cylinder, hermetic sealing, seal.

\section{Introduction}

Sealing property of hydraulic power cylinders, which include hydraulic jacks and powered support props, is determined by the size of the gap between the piston and working cylinder, as well as by the operation of lip-type seal in this gap.

This paper present comparative assessment of performance of three seals, made according to the State Standard 6678-72, State Standard 14896-84and State Standard 6969-54, which differ in shape and geometrical dimensions.

\section{Work Description}

The assessment of seal parameters of the sealed gap was made on parametricaxi symmetric finite element model of the seal assembly; the initial parameters being geometric dimensions of lip-type seal and lip seal groove of the piston; sealable gap, material properties, the worting fluid pressure.

As the working fluid was adopted waterin-oil emulsion, sealing pressuro$50 \mathrm{MPa}$ Since the lip-type seal of hydranlic powered props lip is made of low-compressibility material, the Mooney-Rivlin model with two parameters is most suitable to describe its behavior.

According to the model the calculation was carried out in two stages: on the first stage the deformed state of lip-type seal after the cylinder assembly was simulated (Fig.1); on the second stage- from the working fluid effect in the form of distributed load on the internal sealing surfaces (Fig. 2).

a

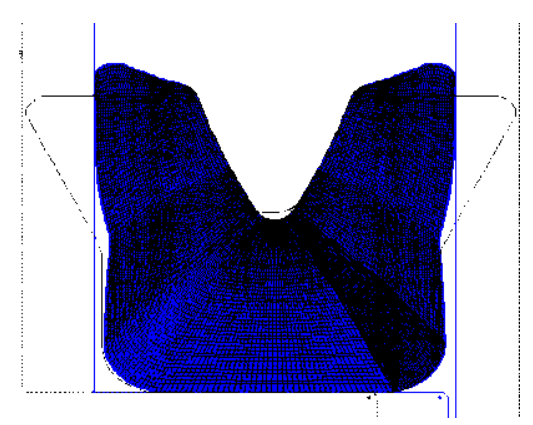

6

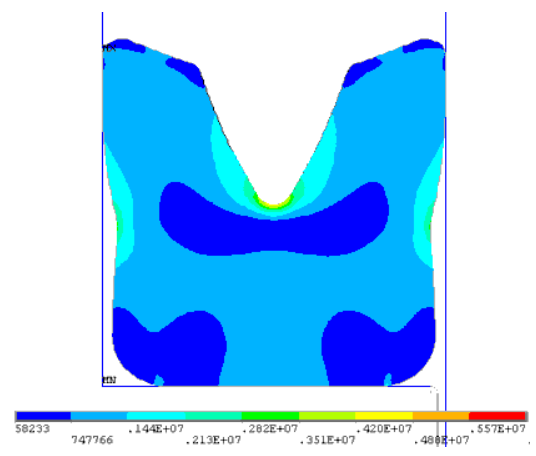

Fig. 1: Deformations (a) and load distribution according to Mises $(\sigma)$ in the lip-typo seal on the basis of State Standand 6969-54 after assembly. 
a

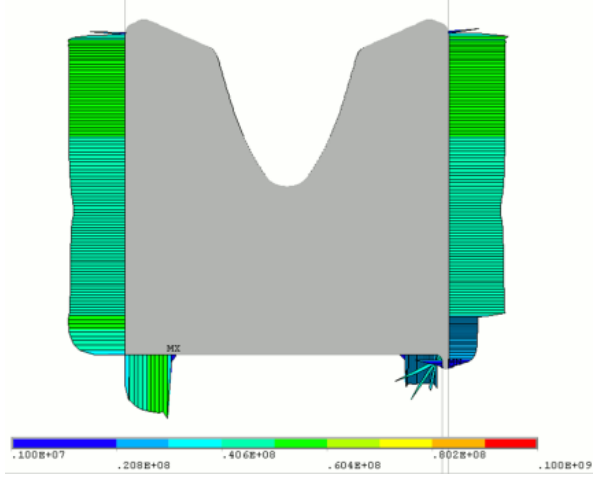

б

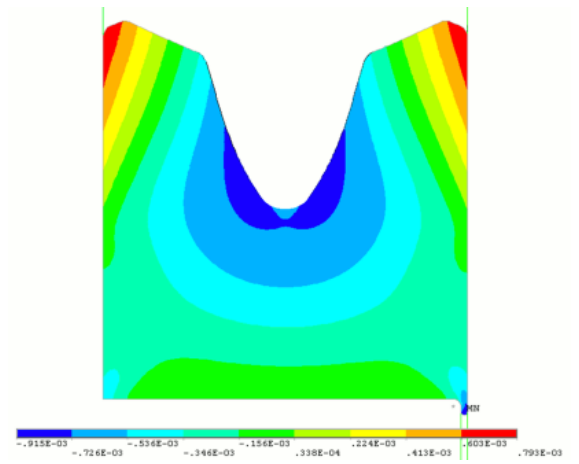

Fig. 2: Axial movement (а) и contact pressure (б) in the lip-type seal on the basis of State Standard at working fluid pressure $50 \mathrm{MPa}$.

For reliable liquid blockage the seal parts should adjoin tightly the details conjugate to them by means of preload and the working liquid pressure. The sealing parts must fit all mechanical regularities and to prevent the formation of the gap through which the fluid could leak when moving. On this basis, the following criteria for assessment of the parameters of the seal operation are proposed ${ }^{[1]}$ :

- $\quad$ seal load factor $[n]=\frac{[\sigma]}{\sigma_{\max }}$ where $\sigma_{\max }$ and $[\sigma]$ and maximum and allowable equivalent loads in the seal respectively, $\mathrm{MPa}$; value of seal material pressing-out into the gapL $\mathrm{s}_{\mathrm{s}} \mathrm{mm}$; relative value of seal material pressing-out into the gap, equal to the previuos value, relative to the gap $K_{3}=\frac{L_{s}}{\delta}$;maximum contact pressure across the sealable surface $p_{\kappa}^{\max }, \mathrm{MPa}$;

- $\quad$ working fluid blockage coefficient

$$
\mathrm{K}_{3 \mathrm{I}}=\frac{\bar{p}_{\mathrm{\kappa}}}{p},
$$

where $\bar{p}_{\kappa}-$ average contact pressure across the sealable surface, $\mathrm{MPa}$; $\mathrm{p}$ - working fluid pressure, MPa.

Criteria values calculated using the developed parametric model for various types of lip-type seal when the piston diameters of $220 \mathrm{~mm}$ and gap size is of $\delta=0.25 \mathrm{mmare}$ shown in Table1.

Table 1: Seal operation criteria values in the sealed gap

\begin{tabular}{|l|c|c|c|c|c|}
\hline \multicolumn{1}{|c|}{ Seal type } & $\begin{array}{c}\text { Load } \\
\text { factor } \\
\mathrm{n}_{\text {зп }}\end{array}$ & $\begin{array}{c}\text { Pressing-out } \\
\text { into the gap } \\
\mathrm{L}_{3}, \mathrm{~mm}\end{array}$ & $\begin{array}{c}\text { Pressing-out, } \\
\text { relative to } \\
\text { the gapK }\end{array}$ & $\begin{array}{c}\text { maximum contact } \\
\text { pressure } p_{\kappa}^{\mathrm{max}} \\
\mathrm{MPa}\end{array}$ & $\begin{array}{c}\text { working fluid } \\
\text { blockage } \\
\text { coefficient } \mathrm{K}_{3 \Pi}\end{array}$ \\
\hline $\begin{array}{l}\text { StateStandard } \\
6678-72\end{array}$ & 3.1 & 1.06 & 4.2 & 56.7 & 1.13 \\
\hline $\begin{array}{l}\text { State } \\
\text { Standard } \\
\text { 14896-84 }\end{array}$ & 4.9 & 0.75 & 3.0 & 48.9 & 0.97 \\
\hline $\begin{array}{l}\text { State } \\
\text { Standard } \\
6969-54\end{array}$ & 3.9 & 0.63 & 2.5 & 57.1 & 1.14 \\
\hline
\end{tabular}


As the table shows, the value of seal material pressing-out into the gap and Pressing-out, relative to the gapthe give the most complete assessment of seal operation in the sealed gap.

The evaluation of operation of the seal in the gap between the piston and the cylinder using the finite element method is a laborious process ${ }^{[2,3]}$. This is due, primarily, to the nonlinearity of the outer surface of the seal and the related additional complexity of creating a regular finite element mesh, as well as to with large model formations (especially in the gap), which reduce the probability of the solution convergence.

In order to eliminate these difficulties the simplified model of lip-type seal was developed (Fig.3), which differs from the real one in the absence of "antennae". The accuracy of the results obtained on the basis of the simplified model in the gap area does not differ from the results obtained on the basis of a real model; at the height of the model being not lower then (B_up) the height of the main body of the lip-type seal. The errorin the calculationis about $0.05 \%$.

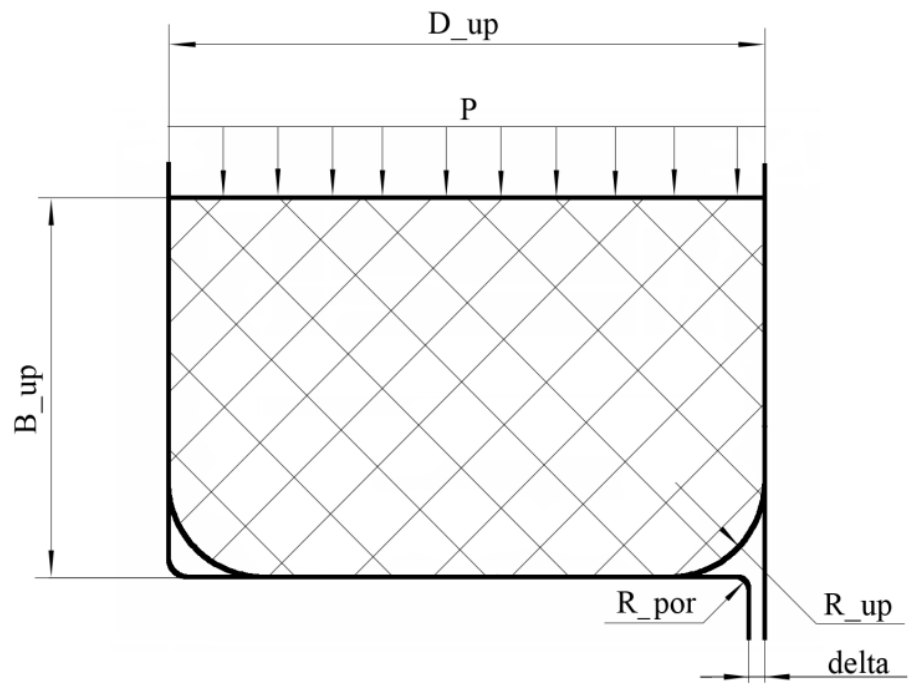

Fig. 3: The simplifiedmodelof seal assembly of hydraulicpowered support prop

The developed model allows taking into account the following parameters (Fig. 3): -geometrical dimensions: height (B_up), width (D_up), seal rounding radius(R_up),

spherical radius of the groove edges of the piston(R_por);

- sealed gap (delta);

- properties of the seal material;

- the fluid pressure in piston cavity of the of hydraulic powered support prop (P).

\section{Conclusions}

On the basis of the calculations using the simplified models the basic regularities and the mode of lip-type seal behavior in the gap are found:
- pressing out into the gap and equivalent loads vary according to the linear relationship in direct proportion to the spherical radius of the groove edges of the piston(R_por), sealed gap, the fluid pressure and inversely to the spherical radius of the seal(R_up);

-the maximum equivalent loads are in the immediate vicinity to the edges of the groove of the piston(Fig. 4);

- the height increase lead to a slight decrease (within $0.001 \mathrm{~mm}$ per $1 \mathrm{~mm}$ of height) of the quantity of pressing out into the gap, wherein the internal load increases ( $0.1 \mathrm{MPa}$ per1mm of height);

- the $10 \mathrm{MPa}$ pressure increase results in an $0.1 \mathrm{~mm}$ increase of the value of the 
pressing out into the gap and $5 \mathrm{MPa}$ increase of the internal load.

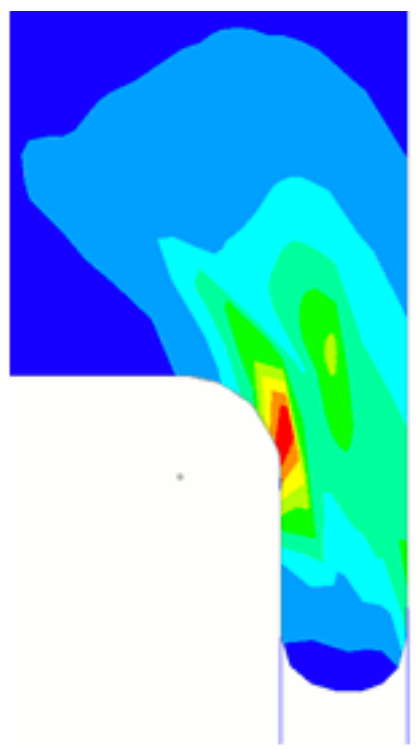

Fig. 4: Mode of deformation of the seal bear the gap

\section{Reference}

[1] Buyalich, K. G. Criteria of an estimation of quality of work of consolidation of hydraulic legs of powered support// Mining equipment and electromechanics. - 2009. - № 5. $-8-10$ p.

[2] Aleksandrov B. A.Influence of geometrical parameters of sealing on expression size in cylinder clearance / B. A. Aleksandrov, K. G. Buyalich // Mininginformationalandanalyticalbulletin (scientificandtechnicaljournal). - 2010. Specialedition 3: Mining engineering. 88-92 p.

[3] Buyalich, G. D.Regular lattice of finit elements collar seals hydro desk / G. D. Buyalich, K. G. Buyalich// Mining informational and analytical bulletin (scientific and technical journal). - 2012. -Special edition 3: Mining engineering. 119-121 p. 